\title{
Washington, la legitimación cubana y la paradoja de Allende
}

\section{Washington, Cuba's legitimacy and the Allende's paradox}

\author{
Joan del Alcàzar Garrido ${ }^{1}$ \\ Indira Betancourt López ${ }^{2}$ \\ Universitat de València (España)
}

Recibido: 21-05-15

Aprobado: 16-06-15

\section{Resumen}

La llamada Vía chilena al socialismo, hoja de ruta del gobierno de la Unidad Popular presidido por Allende, constituyó una propuesta doblemente hipotecada por condicionantes externos. Por una parte, el continente era un territorio bajo jurisdicción indiscutible de los Estados Unidos, en un escenario mundial de Guerra Fría; por otra, el paradigma anticapitalista continental era la

\footnotetext{
${ }^{1}$ (jalcazar@uv.es). Licenciado en Historia, Doctor en Historia por la Universitat de València, es catedrático en el Departamento de Historia Contemporánea, adscrito como investigador al Institut Interuniversitari de Desenvolupament Local de la Universitat de València. Publicaciones recientes: Joan del Alcàzar: "Pinochet vs. Allende. Imágenes para la juventud del siglo XXI", (Libro): J. del Alcázar y E. Valenzuela, eds., Chile 73. Memoria, impactos y perspectivas, Editorial: PUV/Universidad Alberto Hurtado, 2013; Chile en la pantalla. Cine para escribir y para enseñar la historia (1970-1998), Valencia/Santiago, PUV/Centro de Investigaciones D. Barros Arana, Chile, 2013; Joan del Alcàzar Garrido; Sergio López Rivero "Fidel Castro, cuatro fases de un liderazgo inacabado", Araucaria. Revista Iberoamericana de Filosofía, Política y Humanidades, Año 15, nº 30, pp. 3-24, 2013. Joan del Alcàzar y Sergio López Rivero: "Castro contra Castro. Reflexiones sobre una revolución desfigurada, 1989-2014”, Revista Encrucijada americana, (Chile) Volumen: 6 Número: 2, pp. 9-23, 2014; Joan del Alcàzar: "Una realidad social escindida. Las memorias de las peras y las manzanas en el Chile reciente", Revista Historia 2.0, Conocimiento Histórico en Clave digital (Colombia), Año IV, N ${ }^{\circ} 7$, 2014; Joan del Alcàzar: "Memoria para el futuro contra memorias obstinadas. Chile cuarenta años después", Universitas. Revista de Ciencias Sociales y Humans de la UPS (Ecuador) 2014.

${ }^{2}$ (inbelo@uv.es). Licenciada en Historia por la Universidad de Oriente, Cuba (2008), Máster en Estudios Cubanos y del Caribe (2010), Máster en Cooperación al Desarrollo por la Universitat de València (2015), miembro del grupo de investigación LOCSUS Institut Interuniversitari de Desenvolupament Local de la Universitat de València. Publicaciones recientes: Nuevos Estudios Históricos Culturales. Ediciones Santiago, (Cuba) 2009; "Cienfuegos cuna de Presidentes", Revista Santiago (Cuba) 2010; El Derecho como saber cultural. Homenaje al Dr. Delio Carreras Cuevas, Editorial de Ciencias Sociales, La Habana, 2013; Reseña a Chile en la pantalla, 1970-1998. Cine para escribir y para enseñar historia, en Revista Mensaje (Chile) 2014; "Las imprescindibles sinergias entre los diversos actores políticos y sociales en pos del desarrollo local en Cuba" en Nueve estudios hispano cubanos sobre el desarrollo local, eds., Editorial de la Universitat de Valencia, Publicacions de la Universitat de València, 2015.
} 
Cuba revolucionaria. La paradoja de Allende consistió en que mientras que para Washington Allende era un revolucionario contrastado, para los cubanos y sus seguidores era poco más que un reformista. Solo le reconocieron plenamente su condición de revolucionario cuando se inmoló en La Moneda. Allí quedó claro que en América Latina no había otra forma de ser auténticamente revolucionario y alcanzar el socialismo que la establecida por el canon cubano: la lucha armada.

Palabras-clave: Chile, Cuba, Allende, Castro, Revolución, Washington

\begin{abstract}
The so called Chilean Way to socialism, waybill of Popular Unity government headed by Allende, was a proposal double conditioned by external factors. On the one hand, the continent was a territory under undisputed jurisdiction of the United States within a Cold War scenario; on the other hand, the continental anti-capitalist paradigm was the revolutionary Cuba. Allende's paradox was that while for Washington he was a contrasted revolutionary, for the Cubans and their followers he was little more than a reformer. They only fully recognized his status as revolutionary when he blew himself up to La Moneda. From this fact, it became clear that the only way to be truly revolutionary and achieve socialism was that one established by the Cuban canon in Latin America: the armed battle.
\end{abstract}

Key-words: Chile, Cuba, Allende, Castro, Revolution, Washington

Tras la victoria revolucionaria de los insurgentes cubanos y, específicamente, tras que su máximo líder, Fidel Castro, estableciera que no había otra forma de hacer la revolución en América Latina que mediante la lucha armada ${ }^{3}$, cualquier propuesta transformadora que hubiera de ponerse en marcha en el Continente había de contemplarla. El axioma definitivo se santificó en 1967, en la reunión de la Organización Latinoamericana de Solidaridad (OLAS) celebrada en La Habana, cuando Castro afirmó que mentían quienes afirmaban que la revolución se podía hacer por la vía pacífica.

La OLAS había sido creada en agosto de 1967 en Cuba, pocas semanas antes de la muerte del Che Guevara en Bolivia. La formaban diversos grupos revolucionarios continentales alineados, más o menos, con la estrategia revolucionaria cubana. En aquella reunión de La Habana se evidenciaron las

${ }^{3}$ El Comandante en Jefe Fidel Castro habla sobre la Lucha Armada, en una entrevista de 1967. Vid. https://www.youtube.com/watch?v=3wM6io-a9rQ\&feature=related [13.05.2015].

Araucaria. Revista Iberoamericana de Filosofía, Política y Humanidades, año 17, no 34. Segundo semestre de 2015. Pp. 231-251. ISSN 1575-6823 e-ISSN 2340-2199 doi: 10.12795/araucaria.2015.i34.11 
diferencias que había entre los partidos comunistas tradicionales, sensibles a las directrices moscovitas, y otros grupos de la nueva izquierda surgida en América Latina al rebufo cubano. Además, la desaparición del paradigma internacionalista que era el Che unido a la pugna que éste había mantenido con Mario Monge, el líder del PC de Bolivia, impidió que la Organización cuajara con el peso y la influencia que habían querido sus impulsores. No obstante, sí quedó claro que el sector influido por los cubanos apostaba claramente por la guerra de guerrillas como mecanismo para extender la revolución a toda Latinoamérica.

El modelo cubano estaba claro. Jóvenes convertidos en revolucionarios por su oposición a la dictadura de Fulgencio Batista, de procedencia urbana y de clase media, se lanzaron a las montañas declarando la guerra al gobierno y se dieron de bruces con las duras condiciones de vida de los campesinos de la Sierra Maestra. Esos guerrilleros de la Sierra se esforzaron en ganar la simpatía de estos campesinos pobres, tanto para asegurarse víveres y descanso como para evitar la delación a los militares. En poco tiempo Fidel Castro cambió de estrategia, y el Movimiento Revolucionario 26 de julio pasó de realizar ataques esporádicos con huida posterior, a una nueva fase de mayor agresividad militar contra el ejército.

La respuesta del gobierno, la que pretendía que fuera la definitiva ofensiva que aniquilara a los guerrilleros, concluyó en un rotundo fracaso. Unidades militares enteras fueron capturadas por los insurgentes junto a sus códigos secretos, el armamento y la munición. En consecuencia, la respuesta del régimen fue establecer el terror ${ }^{4}$. Con tal fin, toda la fuerza represiva se concentró en arremeter contra los principales sospechosos (los estudiantes y la clase media, singularmente) de colaborar con los barbudos de la Sierra Maestra del Movimiento Revolucionario 26 de Julio. Por ello, las agresiones fueron dirigidas fundamentalmente a las universidades y los colegios de enseñanza media. Los efectos de esta sangría se hicieron sentir y, contrariamente a lo que se esperaba por parte del gobierno de Batista, hubo un aumento exponencial del prestigio del líder del M26J, Fidel Castro, al tiempo que más voluntarios engrosaron las filas del ejército rebelde y reforzaron la lucha clandestina en todas las ciudades del país.

Para sorpresa de muchos, pocos meses después del triunfo el 1 de enero de 1959, la Revolución se definía públicamente como una revolución de los obreros y los campesinos ${ }^{5}$, una premisa ideológica que rompía radicalmente la retórica enarbolada hasta ese entonces. De esta forma fueron adoptadas

\footnotetext{
4 Vid. Alcázar Joan y López Rivero Sergio: "Fuego cruzado. Guerrillas, dictaduras militares y violaciones masivas de los derechos humanos" en Alcázar Joan (ed): Historia Actual de América latina 1959-2009, pp. 49-100

5 Ídem. Un viraje aceptado hasta por el viejo partido de los comunistas cubanos, que realizó la conveniente autocrítica, reconociendo que sus esquemas políticos eran deudores en exceso del modelo revolucionario ruso.

Araucaria. Revista Iberoamericana de Filosofía, Política y Humanidades, año 17, n 34. Segundo semestre de 2015. Pp. 231-251. ISSN 1575-6823 e-ISSN 2340-2199 doi: 10.12795/araucaria.2015.i34.11
} 
pautas de funcionamiento opuestas al discurso anterior a $1959 \mathrm{y}$ en su lugar se produjo una réplica caribeña de las estructuras políticas de la antigua Unión Soviética, las que permanecieron intactas hasta la desaparición de ésta el 25 de diciembre de 1991.

Se estableció un gobierno ultranacionalista con políticas socioeconómicas igualitarias que se apoyó fundamentalmente en el intercambio comercial con el Consejo de Asistencia Económica Mutua (CAME). Junto a eso, el caudillismo de Fidel Castro, aderezado con una buena dosis de retórica marxista-leninista, permitió organizar el nuevo Estado alrededor del centralismo democrático, con una clara jerarquía estratificada alrededor del liderazgo de su organización política ${ }^{6}$.

En síntesis, podríamos decir que el modelo cubano se resumía en una combinación de lucha armada para lograr el acceso al poder, una ruptura completa y radical con el orden político anterior, el establecimiento de un régimen autoritario de partido único, la implementación de una economía fuertemente centralizada y, además, una exclusión total de los creyentes en los distintos ámbitos políticos y sociales.

Se comprende con facilidad que, con estos parámetros como características constitutivas del canon revolucionario, la llamada Vía Chilena al Socialismo, auspiciada por una coalición de izquierdas denominada Unidad Popular, comandada por el médico socialista Salvador Allende, estaba casi en las antípodas. Tanto que casi parecía una copia en negativo, como el reverso de la vía cubana. Desde la teoría al menos, solo el objetivo final era coincidente: el socialismo. Ambos tenían en él la parada final del viaje, y a las alturas de 1970, cuando Salvador Allende llegó a la presidencia de la República de Chile al frente de la coalición, los cubanos ya se habían instalado en él: Cuba ya era un país socialista. Chile aspiraba a serlo, conducido por el doctor Allende.

Los mimbres políticos y partidarios en la costa del Pacífico eran muy distintos respecto de los del Caribe. No solo no se proponía la lucha armada para acceder al poder, sino que el gobierno de Chile se había alcanzado democráticamente, en unas elecciones multipartidarias; no solo no se había establecido una ruptura tajante con el período anterior, sino que el nuevo gobierno chileno, fiel a su programa electoral, aseguraba la continuidad institucional acorde con el escenario político constitucional; pese al establecimiento del Área de Propiedad Social y de una política de nacionalizaciones junto a otras medidas en política económica, en Chile no se estableció un sistema económico centralizado y la propiedad privada siguió existiendo; finalmente, en materia religiosa, la Unidad Popular no solo no proscribió a los creyentes, sino que además de la presencia política efectiva del movimiento Cristianos por el Socialismo, buena parte de los dirigentes de los partidos de la UP eran creyentes practicantes.

\footnotetext{
6 Ídem.
} 
No sorprende, pues, que con estas grandes diferencias entre lo que constituían los muros de carga que sustentaban el edificio político cubano y los que sustentaban el chileno, este último levantara sospechas y suspicacias respecto a su reconocimiento como régimen revolucionario. El gobierno presidido por Salvador Allende trataba de ser reconocido como un gobierno revolucionario, mientras que la sombra del reformismo planeaba sobre él, cuanto menos al contemplarlo desde la ortodoxia establecida por el canon cubano.

Efectivamente, de acuerdo con la pauta canónica, la conocida como Vía chilena al Socialismo había arrancado con un notable déficit de legitimidad revolucionaria, tanto más en la medida que se había integrado en una lógica parlamentaria, resultante de un proceso electoral propio de la llamada democracia burguesa. Ese estigma, ese pecado original que los guardianes de la ortodoxia recordaron a Allende cada vez que tuvieron ocasión, forzó al líder chileno a rebatir con vehemencia la acusación de reformista, mientras que con la misma fuerza reivindicaba su condición de verdadero revolucionario.

Fueron muchas las ocasiones en las que el líder socialista chileno hubo de enfrentarse a las descalificaciones de quienes lo acusaban de no ser lo suficientemente revolucionario, y otras tantas en las que Salvador Allende las desmintió incluso con rabia. Además, el presidente chileno siempre insistió en que su objetivo era el de llegar al punto al que Cuba ya había llegado bajo la dirección de Fidel Castro, aunque el camino fuera distinto. Allende exhibió sus relaciones con el Che Guevara, con Ho Chi Min y con otros líderes de la izquierda internacional como un aval de su posición inequívoca, pero convencido como estaba que era Fidel Castro quien oficiaba de sacerdote de la ortodoxia, fue a éste a quien se encomendó en más de una ocasión y de quien reclamó que avalara su acción revolucionaria, que no reformista.

Por ejemplo, en un acto conjunto de ambos líderes realizado en Puerto Montt, el 18 de noviembre de 1971, el líder chileno estaba hablando a la multitud congregada en la capital de la Región de Los Lagos, en presencia de Fidel Castro. Estaba alabando "la importancia transcendente de la lucha del pueblo cubano", al tiempo que rendía "homenaje a la abnegación revolucionaria de sus conductores", pero había afirmado "que la herencia de Cuba no es realidad de Chile; que nosotros teníamos que hacer nuestro propio camino", cuando fue interrumpido por los gritos de una parte de los asistentes ${ }^{7}$.

Visiblemente molesto, Allende se dirigió al público diciendo: "La Revolución en Chile no se hace solamente gritando revolución, la revolución se hace conscientemente, con un pueblo organizado que sabe los riesgos que tiene que aceptar [aplausos]. Y por último, les voy a decir a los compañeritos que gritan revolución, que Fidel Castro no estaría en Chile si aquí no hubiera

${ }^{7}$ Fidel en Chile. Textos completos de su diálogo con el pueblo. Santiago de Chile, Empresa editora nacional Quimantú ETDA, 1972, pp. 126-127.

Araucaria. Revista Iberoamericana de Filosofía, Política y Humanidades, año 17, $\mathrm{n}^{\circ} 34$. Segundo semestre de 2015 Pp. 231-251. ISSN 1575-6823 e-ISSN 2340-2199 doi: 10.12795/araucaria.2015.i34.11 
triunfado un gobierno revolucionario [aplausos]. Fidel Castro no se prestaría para la farsa de venir aquí a visitar un país de oportunistas y a un gobierno claudicante".

De manera explícita, el presidente chileno concedía al líder cubano la validación del carácter no reformista de su gobierno y de su propuesta política para conducir a Chile al socialismo, atendiendo, eso si, a las singularidades nacionales: "Él [Fidel] tiene consciencia y sabe que lo que hacemos nosotros es una revolución de acuerdo con nuestra realidad [aplausos] y por eso, es que está presente el compañero y amigo, Jefe de la Revolución cubana". Reforzando la idea del incuestionable cariz revolucionario de la experiencia política que Chile estaba viviendo, Allende afirmó: "Yo no soy un Presidente más, yo soy un Presidente del Gobierno Popular, nacional y revolucionario que debe decirles que hemos cumplido y que el pueblo está en el gobierno" [aplausos y gritos]".

No quiso perder la ocasión el dirigente chileno, además, de recordar su currículum a los reunidos, particularmente a aquellos que le habían irritado: "Y nosotros hemos luchado, conscientemente, desde hace largos años, antes que nacieran, no digo a la vida política, sino a la vida física, algunos jóvenes de esos que hacen gárgara con la palabra revolución, ya me enfrentaba a los imperialistas y había sido expulsado de la universidad para tener que ir a luchar junto al pueblo" [aplausos] $]^{10}$.

En sintonía con la idea central de la citada intervención de Allende, el propósito de estas páginas es profundizar en el análisis de ese combate que el líder chileno libró contra la imagen de político reformista, -un menchevique en el mejor de los casos- que tenía entre buena parte de sus más o menos correligionarios, tanto de dentro como de fuera de Chile. Y vamos a hacerlo centrándonos en tres acontecimientos importantes relacionados con su persona. Dos de ellos en vida y el último tras su muerte. También son dos los que están coprotagonizados por quien tenía la patente de la revolución en América Latina, el -en palabras del propio Allende- Comandante de la Esperanza Latinoamericana. En el tercero, -y a él nos referiremos acto seguido, porqué fue el primero en producirse cronológicamente-, el doctor Allende estuvo acompañado por un incómodo y casi inquisitorial visitante: el joven filósofo francés Regis Debray, quien venía de Cuba con el medidor revolucionario bien engrasado para aplicárselo a Allende.

\footnotetext{
${ }^{8}$ Ídem, p. 127

${ }^{9}$ Ibídem.

${ }^{10}$ Ibídem.
} 


\section{El examen del filósofo petulante}

Si repasamos este encuentro ${ }^{11}$ podemos percibir a un entrevistador soberbio y prepotente, que actuó de forma reiterada como un evaluador del proceso político chileno y de las dimensiones de la radicalidad de su presidente. En la entrevista hubo varios momentos que podríamos señalar como representativos; por ejemplo cuando Debray afirma que, en su opinión, el gobierno de la UP "es la expresión y el producto histórico de un desarrollo muy especial, que ha combinado las formas políticas de la democracia burguesa con un amplio movimiento social proletario", a lo que Allende replica "que nuestros problemas de fondo no podían solucionarse porque nuestras riquezas esenciales están en manos del capital extranjero". Añadiendo más adelante que gracias a la Revolución cubana habían podido ver "con más claridad todavía, lo que es el imperialismo y de qué manera no hay fronteras que lo detengan cuando trata de defender sus intereses" ${ }^{\prime 2}$.

La insistencia permanente y casi humillante de Allende estuvo dirigida a explicarle a su entrevistador que Chile había escogido el camino de la revolución y que lo había hecho de forma rotunda. Una tesis más que discutible, sin duda, ya que la UP solo había obtenido el apoyo del 36 por ciento del electorado [el 64 por ciento, por lo tanto, no lo había avalado con su voto]. Más allá de este importante dato, que fue omitido durante la entrevista, el presidente insistió en que había sido el pueblo quien le había votado para cambiar "el régimen y el sistema, para conquistar el Gobierno, para conseguir el poder".

Así mismo, en el transcurso de la entrevista se pueden notar dos ideas recurrentes en el discurso del presidente chileno: por una parte establece una clara separación respecto a sus opositores políticos y, por otra, sostiene que hay un punto de no retorno en la conciliación. Es importante este aspecto ya que parece dar por supuesto el enfrentamiento entre ambos sectores meses antes, incluso, de la visita de Castro a Chile, una estancia que tradicionalmente ha sido considerado como el punto de partida de la polarización y la fractura de la sociedad chilena. Se trata de un posicionamiento que parece demasiado forzado, incluso imprudente y poco acorde con la realidad política chilena a principios de 1971.

${ }^{11}$ La entrevista que el joven francés y el maduro presidente mantuvieron fue grabada a petición de Allende bajo la dirección del cineasta Miguel Littin. Se trata de Compañero presidente, un documento extraordinario para avanzar tanto en el conocimiento de la Vía chilena como para profundizar en el clima político ideológico de la izquierda transformadora en aquellos años en los que el capitalismo parecía un sistema agotado y el socialismo estaba al alcance de la mano. Vid Alcàzar Joan: Chile en la pantalla, cine para escribir y para enseñara la historia (1970-1998), Valencia-Santiago, PUVDirección de Bibliotecas y Archivos de Chile 2013, p. 93

${ }^{12}$ El filósofo francés publicó un libro con parte de los contenidos de esa entrevista. Se trata de Debray, Regis: Conversación con Allende, México: Siglo XXI, 1971.

Araucaria. Revista Iberoamericana de Filosofía, Política y Humanidades, año 17, n 34. Segundo semestre de 2015. Pp. 231-251. ISSN 1575-6823 e-ISSN 2340-2199 doi: 10.12795/araucaria.2015.i34.11 
Frente al optimismo de Allende ante lo que sería el resultado del conflicto político en Chile cuando se produjera la mencionada ruptura, su incisivo entrevistador pregunta: "¿Se producirá un enfrentamiento total [con la reacción]?", a lo que Allende responde: "Enfrentamientos hay todos los días, pero el [enfrentamiento] total, dependerá de ellos. Si ellos lo provocan, se va a producir. Pero nosotros dejaremos que ellos lo provoquen, pero estaremos vigilantes. Sabemos perfectamente lo que la historia señala [sic] y no nos van a pillar de sorpresa".

Pareciera que el Presidente Allende afirmaba que la Vía chilena al Socialismo transitaría inevitablemente por los cauces institucionales en tanto la "reacción" no les forzara a usar la violencia. Una idea atrevida si tenemos en cuenta que la correlación de fuerzas en las urnas había sido -como hemos dicho- de 36 a favor y 64 en contra. Cabe preguntarse entonces si realmente el presidente sentía que contaba con la neutralidad de las Fuerzas Armadas o sencillamente tenía un plan oculto alternativo para, por ejemplo, armar a sus partidarios en caso de que se produjera el anunciado choque violento.

Tras la cita de Lenin que le hiciera Debray: "hay reformas que favorecen la revolución y reformas que la frenan", argumentando que actuar bajo la sombra de la Carta Magna burguesa no era otra cosa que reformismo, Allende reaccionó a la defensiva: "Yo creo que nosotros hemos utilizado aquellas [reformas] que le abren el camino a la revolución. Ahora tenemos la pretensión, y eso si que lo voy a decir con modestia, de estar creando un camino distinto, y demostrar que se puede hacer". En la defensa de su posición, persiguiendo que ésta fuera homologada por Debray, el socialismo del que Allende hablaba era el del modelo cubano ${ }^{13}$. Ese tipo de discurso, como era de esperar, tuvo múltiples y variados efectos tanto entre la oposición, que se sintió claramente amenazada, como entre la parte más radicalizada de la UP, a la que consiguió enardecer. En conclusión: a una parte de sus adeptos les llevó a desear mayor coincidencia en la táctica; y a la totalidad de sus contrarios les horrorizó la estrategia.

Tras la visita de Fidel Castro en noviembre de 1971 -meses después de la conversación con Debray-, se acrecentó la radicalización de la oposición a Allende. Entre sus enemigos se generalizó la convicción de que el presidente de la República era un potencial aspirante a engrosar la nómina de líderes comunistas en el mundo.

${ }^{13}$ En este sentido, sus enemigos siempre miraron con recelo las amistades del presidente. Sobre la influencia y admiración que sentía por distintos líderes comunistas, Allende dijo: "Dos personas me han impresionado por algo que no he encontrado en otros, su mirada, Chu En Lai y el Che Guevara. En ambos había una fuerza interior. En ambos había firmeza. En ambos había ironía. Yo cuando conversaba con el Comandante Guevara y lo miraba sabía la respuesta antes que él la dijera con sus palabras". También sintió fascinación por el líder vietnamita Ho Chi Minh, al que llegó a conocer y del que dijo que era "un anciano, de una dignidad, de una cosa transparente, de una modestia increíble". Alcàzar, Joan y Rodrigo Berta: "Allende vs Pinochet, imágenes para la juventud del siglo XXI" en Alcázar, Joan y Valenzuela, Esteban (eds): Chile 73 Memoria, impactos y perspectivas, pp. 184-185. 
Allende, pese a todo, no pareció entender contradicción alguna entre la defensa cerrada que él hacía de la democracia y la deriva cubana de la que hacía gala. Él decía creer en la posibilidad de llegar al socialismo sin que hablaran las armas, en un proceso que fuese totalmente democrático y votado en las urnas: "Nosotros vamos a hacer una democracia auténtica, porque va a participar el pueblo, y no una minoría como hasta ahora. Ahora, cuando un pueblo tiene conciencia de las metas que debe alcanzar ese pueblo es capaz de sacrificios [...]. El pueblo va a responder, ese es el gran aval que tengo yo: la entereza, el patriotismo y la moral del pueblo chileno ${ }^{14}$.

Y con esa convicción murió. En agosto del 1973, pocas semanas antes del golpe militar, en uno de sus últimos discursos, Allende insistía: "Con tranquilidad de conciencia y midiendo mis responsabilidades ante las generaciones presentes y futuras, sostengo que nunca antes ha habido en Chile un gobierno más democrático que el que me honro en presidir, que haya hecho más por defender la independencia económica y política del país, por la liberación social de los trabajadores" ${ }^{15}$.

\section{El examen del líder jactancioso}

Ya hemos aludido con anterioridad a la visita que Fidel Castro realizó al Chile de la Unidad Popular a finales de 1971. Concretamente, el dirigente cubano llegó a la capital el 10 de noviembre y permaneció en el país hasta el 4 de diciembre, una estancia absolutamente inusual tratándose de un jefe de Estado en visita oficial. La insólita visita, la denominó el chilenista brasileño Alberto Aggio ${ }^{16}$.

Fidel Castro era, por lo menos de manera aparente y a los ojos de la comunidad internacional, el más estrecho aliado de Allende en el continente. En aquella visita cuya duración prevista era de 10 días pero que duró más del doble, el ilustre visitante recorrió de manera incansable el país andino de norte a sur, visitó más de 10 ciudades, protagonizó actos multitudinarios en espacios abiertos y cerrados, dictó conferencias en distintas instituciones, mantuvo innumerables reuniones con organizaciones de la sociedad civil, participó en

\footnotetext{
${ }^{14}$ Entrevista realizada por Augusto Olivares en la Televisión Nacional de Chile en noviembre de 1971 a Salvador Allende y Fidel Castro. El diálogo de América, http://www.panuelosenrebeldia.com. ar/content/view/228/123/

15 Alcázar y Rodrigo, op. cit, p. 186.

${ }^{16}$ Evidentemente, la llegada de Fidel Castro había sido pensada en aquel momento como una forma de fortalecer el gobierno de la Unidad Popular, después que este hubiera alcanzado más de la mitad de los votos de los chilenos en las elecciones municipales del mes de abril. Éste éxito indiscutible significaba que la UP había traspasado la barrera del tercio de los votos conseguidos en 1970. Es necesario apuntar, no obstante, que 1971 fue el año de gracia de la Unidad Popular, durante el cual parecía que un gobierno de izquierda estaba teniendo un éxito sin precedentes en América Latina. Aggio, Alberto: "Uma insólita visita” en História, São Paulo: UNESP, 22 (2), 151-166, 2003.
} 
acalorados debates con estudiantes universitarios y concedió innumerables entrevistas medios de comunicación chilenos y extranjeros.

Nada fue normal, -en la acepción convencional del termino-, en la estancia de Castro en Chile. Su discurso resultó absolutamente inusual para las formas diplomáticas. Inicialmente se presentó como un amigo del proceso chileno para más tarde convertirse en un protagonista del mismo, llegando a afirmar que compartía [con el gobierno de la UP] tanto los aliados como los enemigos en el interior de Chile.

Castro, con su proverbial locuacidad, situó al gobierno de Allende en una posición delicada, tanto por los silencios u omisiones como por las ideas que explícitamente transmitió en la totalidad de sus intervenciones públicas. Puede decirse que Fidel Castro cuestionó la misma esencia del sistema político chileno de una forma que resultó ofensiva para los enemigos de la UP, y difícil de justificar para los partidarios del gobierno. Como apuntó Joaquín Fermandois, tanto como por sus palabras como por sus actitudes el dirigente cubano puso en tela de juicio el sistema político chileno, atacó a sus instituciones y a sus representantes y contribuyó a exacerbar los ánimos políticos internos. En última instancia, Castro se comportó, en la práctica, como un actor más de la política interna chilena y no como un extranjero de visita en el país ${ }^{17}$.

Más allá de las afirmaciones de que no quería entrometerse en cuestiones de política interna, "Fidel no hizo otra cosa"18. Particularmente pidió unidad a la izquierda política, a los trabajadores, a los estudiantes, a las mujeres, a quienes exigió respeto a la sabiduría del enemigo, al tiempo que aseguraba respetar las distintas debilidades del proceso chileno ${ }^{19}$.

En el primer acto multitudinario en el que participó, con los estudiantes de la Universidad de Chile, en Antofagasta, el 12 de noviembre, Fidel Castro ya dejó evidencia de por dónde iban a ir sus mensajes:

Será un cambio de impresiones, en que yo les podré contestar todo lo que les puedo contestar [Risas y aplausos] (...) No olvidemos que yo me siento aquí como si estuviera en una trampa [Gritos y risas] (...) los tramposos pueden (...) utilizar cualquier palabra para traer el recuerdo del chauvinismo, de la demagogia, en lo cual son en verdad bastante prácticos... Bueno, veo un gran número de banderas. Me recuerda los primeros tiempos de la Revolución Cubana [Aplausos]. Conclusión: las conclusiones las sacan ustedes [Risas y aplausos] ${ }^{20}$.

${ }^{17}$ Fermandois, Joaquín. Chile y el mundo, 1970-1973. La política exterior del gobierno de la Unidad Popular y el sistema internacional. Santiago, Ediciones Universidad Católica de Chile, 1985, p. 238.

${ }_{18}^{18}$ Aggio Alberto, Op.cit

${ }_{19}$ Rojas, Alejandra (et al). Salvador Allende: una época en blanco y negro. Buenos Aires: Aguilar/ El País, 1998.

${ }^{20}$ Fidel en Chile. Op. cit, p. 13

Araucaria. Revista Iberoamericana de Filosofía, Política y Humanidades, año 17, $\mathrm{n}^{\circ} 34$. Segundo semestre de 2015. Pp. 231-251. ISSN 1575-6823 e-ISSN 2340-2199 doi: 10.12795/araucaria.2015.i34.11 
Unos días después, el 17 de noviembre, ante los universitarios de Concepción, en un diálogo con ellos, y ante la pregunta de un estudiante sobre "qué errores ve, qué errores son los fundamentales en el proceso que se está librando en Chile"21, Castro respondió:

En realidad yo no soy quien debe juzgar al Gobierno chileno, yo puedo dar mi opinión sobre las cuestiones, si es un proceso reformista o si es un proceso revolucionario, pero les voy a decir una cosa: está muy bien lo que se dice de discutir, no hay por qué tener miedo de discutirlo: correctísimo. Pero entre ustedes, la discusión es entre ustedes, yo no tengo ninguna prerrogativa para participar en ese tipo de discusiones ${ }^{22}$.

No obstante, en la misma respuesta, Castro afirmó más adelante:

Ahora bien, si a mí me dicen qué es lo que ha estado ocurriendo en Chile y, sinceramente, les diría que en Chile está ocurriendo un proceso revolucionario [Aplausos] Y nosotros, incluso a nuestra revolución la hemos llamado un proceso, un proceso que no es todavía una revolución, un proceso es un camino, un proceso es una fase que se inicia (...) hay que caracterizarlo como una fase revolucionaria que se inicia ${ }^{23}$.

Esa fase revolucionaria que Castro estaba dispuesto a conceder al proceso chileno tenía algunas limitaciones transcendentales. La más importante, quizá, la pervivencia de la democracia representativa. En Cuba, dejó de existir por innecesaria:

En nuestro país las decisiones fundamentales no se discuten en un Parlamento. ¡No! Pero se discuten en los centros de trabajo, se discuten en las organizaciones de masas [Aplausos]. (...) Ya en nuestro país cualquier ley importante que tiene que ver con los intereses fundamentales del pueblo la discuten millones de personas (...) Díganme ahora que el parlamentarismo burgués es más democrático que eso, díganme [Aplausos] (...) El pueblo no necesita quienes lo representen, porque el pueblo se representa a sí mismo [Aplausos] El pueblo no necesita quienes tomen decisiones por él. El pueblo toma decisiones por sí $\operatorname{mismo}^{24}$.

Conforme fueron pasando los días de la visita, que a muchos se les hizo eterna, Castro se atrevió a definir lo que realmente estaba ocurriendo en Chile: el fascismo era el enemigo real de la revolución chilena. Fue durante el discurso que pronunció en el acto de despedida que se celebró en el Estadio nacional, el 2 de diciembre.

\footnotetext{
${ }^{21}$ Idem, p. 88.

${ }^{22}$ Ibídem.

${ }^{23}$ Idem, p.89.

${ }^{24}$ Idem, pp. 215-216.
} 
En la noche anterior, tras haberse producido la Marcha de las cacerolas vacías, Allende había decretado el Estado de Emergencia. Su ilustre visitante, no obstante, consideró que esa era una medida demasiado blanda para un suceso tan grave, y pidió mano dura al Presidente. Allende envió un emisario con una orden clara: "Diga a Fidel, con suavidad, que aquí en Chile quien resuelve esas cosas soy yo, de acuerdo con mi leal saber y entender"25.

En el Estadio Nacional, Castro había preguntado retóricamente [a propósito de la situación por la que atravesaba el país] a los miles de asistentes. "¿Acaso les interesa la opinión de un visitante no turista? ¿Me autorizan? [Gritos: ¡Sí!]”26. Entonces, el líder cubano expuso su tesis de la bipolarización perfecta e ineludible:

\begin{abstract}
Están viviendo el momento del proceso en que los fascistas -para llamarlos como son- están tratando de ganarles la calle, están tratando de ganarles las capas medias de la población. En determinado momento de todo proceso revolucionario, los fascistas y los revolucionarios luchan por ganar el apoyo de las capas medias de la población ${ }^{27}$.
\end{abstract}

La visita resultó agotadora para los anfitriones, por definición más contenidos de carácter que el prócer caribeño. Pero no fue solo el ritmo agotador de mítines, reuniones y viajes; ni fue solamente que aquel huésped parecía que no iba a marcharse nunca. El problema fundamental vino de la mano de las injerencias constantes del cubano, de su protagonismo exacerbado, de su fotogenia y de su popularidad. Tiene razón Rojas cuando dice que el contraste entre Allende y Castro era muy fuerte; que el chileno parecía demasiado sensato, demasiado realista al lado del héroe revolucionario. En el mejor de los casos, Allende podía pasar como el tío del héroe ${ }^{28}$. El resultado de la comparación entre ambos líderes era claro: Allende era "el trabajador de la República en deslucido contraste con el Mesías"29.

Y no ocurrió así porque Allende fuera una persona carente de carisma ni de encantos personales. La diferencia de edad jugaba, claro, pero la exuberancia caribeña del Comandante unida a que representaba una experiencia revolucionaria exitosa y sin mácula, no podía sino favorecerlo principalmente en el espacio público. Pese a todo, el Presidente chileno se esforzó en estar a la altura de la situación. Procuró aparecer como un compañero homologable, como un amigo de Cuba y de su revolución, y como un dirigente que aun compartiendo la estrategia difería en la táctica, pero solo por las especificidades chilenas o por las diferencias entre el Caribe y la costa sur del Pacífico.

\footnotetext{
25 Rojas, Op.cit. p. 103.

${ }^{26}$ Fidel en Chile, Op. cit. p. 267.

27 Ibídem.

28 Aggio, op. cit.

29 Rojas, op. cit, p. 100.
} 
Una muestra de ese deseo de confluir, de aparecer en público como un compañero de armas de Castro, como un líder revolucionario que no reformista, la encontramos en el debate televisivo que ambos mantuvieron en un programa especial conducido por el periodista Augusto Olivares, quien se suicidaría en La Moneda poco antes de que lo hiciera su amigo Salvador Allende el 11 de septiembre de $1973^{30}$.

En ese debate histórico, conocido como el Diálogo de América ${ }^{31}$, ambos dirigentes ofrecieron una imagen de camaradería y complicidad que no pudo mantenerse durante todo el tiempo de la estancia. El mandatario chileno siguió insistiendo en que él proceso que él dirigía era inequívocamente revolucionario, aunque las características socio históricas de Chile explicaban las diferencias con el modelo cubano; mientras que el Comandante Castro insistió en dos puntos: el primero la polarización entre revolución o fascismo que, a su juicio, estaba produciéndose en Chile; y el de la larga sombra del imperialismo [los Estados Unidos] que era el enemigo principal de ambos procesos políticos, el cubano y el chileno.

El diálogo de ambos líderes ante las cámaras fue una puesta en escena, fundamentalmente de las coincidencias estratégicas que ambos mantenían, sin que, no obstante, dejemos de reparar en que parece ser el líder cubano el que marca los posicionamientos más polarizados a propósito de la coyuntura chilena. Preguntado por el conductor del programa Augusto Olivares, sobre los obstáculos del proceso chileno, Allende fue muy expresivo:

\begin{abstract}
¿Te das cuenta, Fidel? ¡Tres minutos para definir los obstáculos de una revolución que tiene que hacerse dentro de la democracia burguesa y con los cauces legales de esa democracia...! (...) Obstáculos. ¿Nacen de qué? En primer lugar de una oligarquía con bastante experiencia, inteligente, que defiende muy bien sus intereses y que tiene el respaldo del imperialismo, dentro del marco de una institucionalidad en donde el Congreso tiene peso y atribuciones, y donde el gobierno no tiene mayoría ${ }^{32}$.
\end{abstract}

Allende abundó en el conjunto de las dificultades al proceso chileno tal y como le había pedido Augusto Olivares:

${ }^{30}$ La entrevista puede encontrarse online en https://www.youtube.com/watch? $\mathrm{v}=\mathrm{BLoIwfSV0P}$ Y\&list=PLPgdWwXi1d9v4nneCB7IQQ6x3ihg_Ep5s\&index=5. La transcripción en http://www. panuelosenrebeldia.com.ar/content/view/228/123/(12.03.2015). Un texto interesante sobre aquel encuentro entre los mandatarios chileno y cubano en Luna, Eva: "Allende y Castro: una entrevista para la historia de América Latina”. En Alcàzar, J. Y Tabanera, N. (coord.). Estudios y materiales para la historia de América Latina, 1955-1990. Valencia: Tirant lo Blanch, 1998.

31 Así se le ha denominado tradicionalmente en los círculos de la izquierda latinoamericana. Vid., por ejemplo, http://www.pagina12.com.ar/diario/elpais/1-203184-2012-09-12.html, o http://www. nodo50.org/americalibre/anteriores/21/allende21.htm. También se encuentra en fondos académicos: http://www.dialnet.unirioja.es/descarga/articulo/1104793.pdf.

${ }^{32}$ El diálogo de América, p. 4 http://www.panuelosenrebeldia.com.ar/content/view/228/123/ 
Que las dificultades en el caso nuestro también están en relación ¿con qué? Con una libertad de prensa que es mucho más que una libertad de prensa. Que es un libertinaje de la prensa. (...) No sólo no reconocen sino que deforman, repito, las iniciativas nuestras. Todo esto, teniendo nosotros que respetar las conquistas que el pueblo alcanzó y de las cuales lógicamente hace uso y mal uso la oposición al gobierno popular ${ }^{33}$.

Ante la enumeración de su anfitrión, el revolucionario cubano aludió sin eufemismos a dos de los conceptos más espinosos de su discurso en Chile: el fascismo y la violencia: "Bueno, yo tengo una impresión, que esa resistencia acude a los procedimientos clásicos, además más desarrollados. Es un procedimiento que nosotros calificamos de fascista y que tratan por tanto de ganar masa, con la demagogia si es posible de los sectores más atrasados de las capas humildes, y ganar masa en las capas medias". ${ }^{34}$

Fue Castro quien aludió al problema de la violencia: "Es de esperar, que hagan resistencia, hagan resistencia fuerte e incluso hagan resistencia violenta, de manera que ése es un factor que no se puede descontar en absoluto en la actual situación chilena, a mi juicio, que es el juicio de un visitante" ${ }^{35}$.

En este punto del diálogo, ambos mandatarios coinciden en que -según dicen- la violencia nunca ha sido generada por las fuerzas revolucionarias, y la conversación resulta, cuando menos, sorprendente:

-Salvador Allende: Tú lo has dicho y yo creo que es muy justo; los revolucionarios nunca han generado la violencia. Han sido los sectores de los grupos golpeados por la revolución los que generan la violencia en la contrarrevolución. -Fidel Castro: Mantuvieron los sistemas por la violencia, así los defienden, por la violencia ${ }^{36}$.

Ambos líderes coinciden en que el escenario es complejo y peligroso. La coyuntura determinada por el enfrentamiento entre quienes apoyan al gobierno y quienes se oponen a él es más que preocupante. El líder chileno dice que si los enemigos del gobierno consiguieran derrocarlo: "se caería en el caos, en la violencia, en la lucha fratricida...". Y Fidel Castro añade: "Y en el fascismo" ${ }^{37}$.

Allende, acto seguido, asume la hipótesis del peligro fascista enunciada por su contertulio: "si el fascismo pretende utilizar los medios con que siempre arrasó a los que pretendieron hacer la Revolución, se encontrarán con la respuesta nuestra y mi decisión implacable"38. A continuación repite una de sus frases más célebres: “Tendrán que acribillarme a balazos, como lo dijera

\footnotetext{
33 Ibídem.

34 Ídem, p, 5.

35 Ibídem.

${ }^{36}$ Ibídem.

37 Ídem., p. 8

38 Ibídem.
} 
ayer, para que deje de actuar"39. En ese momento Fidel Castro respondió: "Yo realmente admiro mucho ese pronunciamiento tuyo. Y eso será una bandera para el pueblo"40.

\section{Arrepentimiento y retorno a la fe verdadera}

Las palabras de Salvador Allende respecto a su posible final se cumplieron. Aunque no fue exactamente acribillado a balazos, el líder chileno se suicidó antes de caer en manos de los militares facciosos que atacaban La Moneda en la mañana del 11 de septiembre de 1973.

Desde su autoinmolación, como por encanto, se disiparon todas las dudas, todas las objeciones, todas las descalificaciones que se habían hecho explícitas desde sus propias filas hacia su persona y hacia su proyecto político. Aquellos que le habían cuestionado su blandura, su falta de resolución inequívocamente revolucionaria; los que le acusaban de simple reformista pasaron a hablar de él como el paradigma del republicanismo revolucionario, como el ejemplo a seguir ${ }^{41}$. Como escribiera Manuel Vázquez Montalbán, Allende se convirtió para muchos en el "horizonte de nuestro mundo moral" 42.

Lo que ocurrió el 11 de septiembre de 1973, simbolizado por el desproporcionado asedio a La Moneda facilitó la imagen definitiva que catapultaría a Allende y lo instalaría de una vez por todas entre el grupo de líderes revolucionarios que él admiraba ${ }^{43}$. Encerrado en un edificio desierto, aislado de cualquier apoyo popular, Allende se enfrentaba metralleta en mano a tanques, aviones y tropas bien entrenadas. Aunque el final era imposible de eludir, la rendición, como había anticipado muchas veces en privado pero también en público, no figuraba entre sus alternativas disponibles ${ }^{44}$.

\footnotetext{
39 Ídem., p. 9

${ }^{40}$ Ibídem

41 "La versión expiatoria de Allende y su gobierno tendía a omitir la profundidad de la crisis institucional y la masiva y cada vez más intensa oposición; minimizaba por lo tanto aquella simpatía nada despreciable e, incluso, quizá, mayoritaria que demandaba una "salida" a la crisis sin negar la posibilidad de un Golpe”. Alcàzar, Joan y Cáceres, Gonzalo: “Allende i la Unitat Popular. Cap a una desconstrucció dels mites polítics xilens” El contemporani 1998, pp. 33-41.

${ }^{42}$ Vázquez Montalban, M. “...de lo que fue Santiago ensangrentada”, en El País, Madrid, 02-11-1988, p. 6.

${ }^{43}$ Según el testimonio de muchos protagonistas de los sucesos y a medida que la espiral conflictiva se hacía cada vez más intensa, Allende se empezó a pensar a si mismo como parte de la historia y por lo tanto emplazado en un lugar diferente de la existencia. Según Osvaldo Puccio hijo, Allende tendía el brazo y le decía a su eventual interlocutor: "Toca, esto es mármol". Torres, Maruja, "La nueva batalla de Chile", en El País, Madrid, 11-09-1988, p. 2.

${ }^{44}$ Las omisiones que proyecta esta leyenda dorada son tal vez más numerosas que las exactitudes en las que incurre. En este punto, por ejemplo, insuficientes han sido los análisis relativos a la pertinaz y finalmente decisiva incomunicación entre Allende y la cúpula de la Unidad Popular. Adicionalmente, poco se dice sobre la ausencia relativa de respaldo popular frente al golpe. Del Pozo, José, Rebeldes, reformistas y revolucionarios. Una historia oral de la izquierda chilena en la época de la Unidad Popular, Santiago, Ediciones Documentas, 1992, pp. 262 y ss.
} 
Tras su muerte, tras su ascenso al lugar de privilegio de los grandes líderes de la izquierda mundial resultó necesario deshumanizar a Allende, despojarlo de todas sus vacilaciones, desviaciones y debilidades y convertirlo en una distorsionada proyección de sí mismo: en un héroe de la futura resistencia ${ }^{45}$. Para cumplir tal propósito era necesario ratificar como exclusivamente verdadera una de las versiones disponibles sobre su deceso: Allende había muerto combatiendo ${ }^{46}$. Sitiado por fuerzas superiores, Allende no podía haber perecido como uno de sus más fieles lugartenientes: el periodista Augusto Olivares. El suicidio era una invención del fascismo, Allende había caído en pleno combate, indudablemente asesinado a manos de las fuerzas de asedio al Palacio, dirigidas por el General Javier Palacios.

Quince días después del golpe, el 28 de septiembre de 1973, Fidel Castro pronunció un discurso en la Plaza de la Revolución de La Habana, ante la viuda del líder, Hortensia Bussi, y su hija Beatriz Allende ${ }^{47}$, que se convertirá en la versión oficial de la muerte guerrillera de Allende en La Moneda. Según la cinematográfica narración del líder cubano, Allende había reconocido su error en aquellas horas finales de su vida. Para alcanzar el socialismo no existía otro camino que aquel que se hacía con las armas en la mano, con la lucha armada contra el fascismo y el imperialismo. Si Allende había formado parte de aquellos que habían mentido al pueblo afirmando que era posible alcanzar la meta socialista sin disparar un tiro, la absolución de su pecado le había llegado con la penitencia de su defensa numantina de La Moneda en aquella mañana del 11 de septiembre.

Según Castro, el epílogo de la resistencia en el palacio presidencial ocurrió del siguiente modo:

Mientras el presidente transportaba pertrechos desde la armería, de nuevo se reanuda el ataque aéreo con violencia. Una explosión quebró cristales próximos

\footnotetext{
${ }^{45}$ Vid. Altamirano, Carlos, Dialéctica de una derrota, Ciudad de México, Siglo XX1, 1978.

${ }^{46}$ Allende durante la mañana del 11-S se dirigió al país en cinco oportunidades. Las cuatro primeras a través de radio Corporación mientras la última, sin duda la más importante y también la más extensa de todas, ocurrió a través de los equipos de Radio Magallanes. En su tercera comunicación, realizada a las 08:45, Allende anunció en tono enfático: “.....defenderé el Gobierno porque es el mandato que el pueblo me ha entregado. No tengo otra alternativa. Sólo acribillándome a balazos podrán impedir la voluntad que es hacer cumplir el programa del pueblo. Si me asesinan, el pueblo seguirá su ruta, seguirá el camino con la diferencia quizás que las cosas serán mucho más duras, mucho más violentas", en Quiroga, Patricio (editor). Salvador Allende. Obras escogidas (1970-1973), Barcelona, Editorial Crítica, 1989 , p. 395. Aunque más tarde le verdad del suicidio haya sido suficientemente aclarada, la argumentación en favor del asesinato cobra fuerza a partir de este discurso. vid. Alcàzar y Cáceres, Op. Cit. p. 39.

47 "Discurso pronunciado por el comandante Fidel Castro Ruz, primer secretario del Comité Central del Partido Comunista de Cuba y primer ministro del Gobierno Revolucionario, en el acto conmemorativo del XIII aniversario de los Comités de Defensa de la Revolución, de solidaridad con el heroico pueblo de Chile, y de homenaje póstumo al doctor Salvador Allende, efectuado en la Plaza de la Revolución, José Martí, La Habana, el 28 de septiembre de 1973”, en Timossi, Jorge. Grandes alamedas. El combate del Presidente Allende, La Habana, Editorial de Ciencias Sociales, 1974, pp. 161-226.
} 
al sitio donde se encontraba el presidente, lanzando fragmentos de vidrio que lo hieren por la espalda. Fue ésta la primera herida que sufrió [...] Minutos después los fascistas reanudan violentamente el ataque, combinando la acción de la Fuerza Aérea con la artillería, los tanques y la infantería [...] Tuvo lugar entonces una de las mayores proezas del presidente. Mientras el palacio estaba envuelto en llamas se arrastró bajo la metralla hasta su gabinete, frente a la Plaza Constitución, tomó personalmente una bazuca, la dirigió contra un tanque situado en la calle Morandé -que disparaba furiosamente contra Palacio- y lo puso fuera de combate con un impacto directo (Aplausos) [...] A las 2 aproximadamente logran ocupar un ángulo de la planta alta. El presidente estaba parapetado, junto a varios de sus compañeros, en una esquina del Salón Rojo. Avanzando hacia el punto de irrupción de los fascistas recibe un balazo en el estómago que lo hace inclinarse de dolor, pero no cesa de luchar; apoyándose en un sillón continúa disparando contra los fascistas a pocos metros de distancia (Aplausos), hasta que un segundo impacto en el pecho lo derriba y ya moribundo es acribillado a balazos ${ }^{48}$.

La muerte de Allende fue mucho más humana que la inventada por Castro. Lo que la versión cubana procuró fue la creación del mito del presidente combatiente, un mito que había de resultar incontestable. De este modo, tal y como ha subrayado José Rodríguez Elizondo:

La asignación de una muerte guerrillera para Allende, debía servir como factor movilizador en las luchas políticas chilenas del futuro próximo. No era lo mismo inmolarse en defensa de un 'sistema de mierda'49, como diría García Márquez en una especie de refrito de la versión del discurso de Fidel Castro ${ }^{50}$, que morir combatiendo para que otros guiados por el ejemplo, iniciaran una lucha con objetivos radicales ${ }^{51}$.

48 "Discurso pronunciado por el comandante Fidel Castro...", en Timossi, Jorge, Op.cit, pp. 179182. Esta fue la versión que se mantuvo durante años, como se puede apreciar en Otero, Lisandro, Razón y fuerza de Chile. Tres años de Unidad Popular, La Habana, Editorial de Ciencias Sociales, 1980, pp. 230-231.

${ }^{49}$ La expresión "sistema de mierda", típica del lenguaje de la época, se emparenta con otro slogan utilizado en algunas manifestaciones de adhesión a la Unidad Popular y que rezaba aproximadamente: "Este es un gobierno de mierda, pero es mi gobierno".

${ }^{50}$ El discurso de Castro corresponde a una alocución pronunciada en la Plaza de la Revolución el día 28 de septiembre de 1973. De acuerdo a un autor anclado en la Leyenda Dorada: “...este es el relato más completo y fidedigno de que se dispone sobre el fin del último presidente de Chile", Otero, op. cit. p. 326. El discurso de Fidel Castro, integro, está recogido en el ya citado libro de Jorge Timossi, editado en enero de 1974. Una versión completa del discurso en: Vázquez Montalbán, Manuel, La vía chilena al Golpe de Estado, Barcelona, Ediciones Saturno, 1973.

${ }^{51}$ Rodríguez Elizondo sobre este punto agrega: "Fidel Castro, rindiendo homenaje al presidente caído, vinculaba el fracaso del experimento chileno con su propia y rotunda autoafirmación. Con la reivindicación de posiciones de liderazgo que el nuevo cuadro político global hacía cada vez menos viables. La muerte del presidente combatiendo a "los fascistas", demostraba que él nunca se había equivocado; que sus posiciones siempre fueron las "correctas", y que esa insólita "vía chilena al socialismo" estaba condenada de antemano por las leyes de la dialéctica. Todo esto pudo condensarlo en la frase clave de su versión sobre la muerte de Allende". Rodríguez Elizondo, José, Crisis y renovación de las izquierdas. De la revolución cubana a Chiapas, pasando por "el caso chileno", Santiago, Editorial Andrés Bello, 1995, p. 230 y ss. 


\section{Conclusiones}

En el escenario de Guerra Fría que se vivía en los años setenta del siglo pasado, diseñado por los dos bloques liderados por las superpotencias vencedoras en la última Gran Guerra, había poco espacio para las sutilezas políticas. El sistema bipolar se sostenía sobre dos grupos de países, con dos sistemas políticos y económicos enfrentados. Además, la enorme tensión entre ambos parecía mantener al mundo al borde del abismo, y se entendía que los ciudadanos solo podían aspirar a un efectivo equilibrio del terror. Entre las dos superpotencias se desarrollaba una especie de carrera permanente de armamentos convencionales y nucleares, de intervenciones militares directas e indirectas, de presiones políticas y presiones económicas; y junto a ellas, un deseo confeso de impedir la ampliación del área de influencia del otro en un juego de suma cero.

En el reparto de Yalta, el llamado hemisferio americano era territorio bajo la jurisdicción indiscutible de Washington, de la misma manera que la Europa oriental lo era de Moscú. Se ha dicho tantas veces, que parece un abuso hablar del mundo en blanco y negro, de los buenos y los malos, de los defensores de la civilización cristiana occidental contra los del materialismo ateo. El error que los estadounidenses tuvieron en Cuba, con el cambio de década de los cincuenta a los sesenta, sencillamente, no podía volver a repetirse. El Gran Perro Rojo, según el argot de la Casa Blanca, no podía volver a escarbar en su jardín.

Era un mundo binario y, como hemos dicho, muy poco dado a sutilezas. Quizá algún funcionario de la estación de la CIA en Santiago, encargado de realizar informes para la Agencia, se sorprendiera de la cruda y áspera discusión en torno a si el Gobierno de Allende era reformista o revolucionario. Incluso pudo esbozar media sonrisa cuando supo que los jóvenes del MIR retiraron a Allende el título de compañero, y lo sustituyeron por el de señor. Para el agente, como para sus superiores, Allende era marxista, y marxista era sinónimo de comunista. Punto. No había prácticamente nada más que discutir.

Así pues, una vez más, cuando Allende volvió a optar a la presidencia de la República, en esta ocasión tras el gobierno de Eduardo Frei, los Estados Unidos hicieron todo lo que estuvo en su mano para evitar que el médico socialista accediera a La Moneda. No lo consiguieron, pero no por ello cejaron en su hostigamiento. Es mucho lo que se sabe sobre las idas y venidas de políticos y empresarios de Santiago a Washington, de los encuentros formales e informales entre personal de la Embajada norteamericana y civiles y militares chilenos, sobre los maletines con dinero para pagar propaganda negra o para sobornar voluntades, sobre valijas diplomáticas incluso con armas para cometer delitos ${ }^{52}$.

${ }^{52}$ Kornblum, Peter: Pinochet y los archivos secretos. Barcelona, Crítica, 2004 
Pero resulta particularmente impactante -tanto más en el mundo de la imagen en el que vivimos- revisar las declaraciones del ex embajador norteamericano en Santiago de Chile, Edward Korry, en uno de los reconocidos documentales elaborados por Patricio Guzmán ${ }^{53}$.

El ex embajador, preguntado por quien lo entrevista, afirma que "Nixon ordenó a la CIA impedir que Allende asumiera la presidencia”, cosa que ya sabíamos. Lo que nos interesa poner en valor de estas declaraciones de Korry es lo que dice a propósito de la figura de Allende. Quien fuera embajador de Washington en Santiago no se pregunta si el mandatario chileno era un revolucionario o un simple reformista, lo tenía muy claro: "Allende había dicho que Estados Unidos era el enemigo $\mathrm{n}^{\circ} 1$, y lo repetía sin cesar. Además, era un gran admirador de Castro, había pasado seis meses en China, extasiándose con el trabajo de Mao, admiraba a Ho Chi Minh en Vietnam y era fan del Che Guevara. Sabíamos que aunque Allende parecía actuar de forma legal y constitucional, el objetivo de su política era eliminar toda influencia de Estados Unidos. Hubiese sido una guerra de clases para acabar con la oposición: la burguesía. Una guerra de clases. Hubiera sido eventualmente "fidelismo sin Fidel".

Es decir, que para el entonces representante diplomático de los gendarmes hemisféricos, Allende era un comunista más, un aliado estrecho de Castro y, por añadidura, un colaborador de los soviéticos. Preguntado respecto a si Allende era una amenaza para EEUU, la respuesta confirma nuestra tesis: "Si se considera la creación de un eje Santiago-La Habana en América Latina, en una época en la que las condiciones sociales eran favorables a una revolución que traería desorden y violencia, EUA podía ver en ello una influencia desestabilizadora de alto riesgo y una extensión de la influencia soviética" ${ }^{54}$.

No deja de ser una paradoja que Allende tuviera de sus enemigos el reconocimiento como revolucionario más que potencialmente peligroso; que pasara por ser un hombre que, efectivamente, podía replicar el modelo cubano en la costa sur del Pacífico; que constituyera una amenaza para la seguridad norteamericana, en tanto que artífice de un hipotético eje La Habana-Santiago; y que, al mismo tiempo, sus amigos, sus compañeros en las fatigas de la transformación social le negaran - de facto- las credenciales revolucionarias. Unas credenciales, un reconocimiento que el supremo guardián del canon revolucionario continental solo le concedería después de muerto. Para ello, el líder chileno hubo de arrepentirse de haber sido herético, de haber engañado al pueblo, de haber disentido de la doctrina, de haber afirmado que

${ }^{53}$ Nos referimos a Salvador Allende, vive en la memoria, estrenado el 24 de septiembre de 2004 en Chile. Edward M. Korry, embajador de EE UU en Chile de 1967 a 1971 que durante años fue sospechoso, erróneamente, de colaborar con los militares para evitar que un marxista se convirtiera en presidente en aquel país. http://elpais.com/diario/2003/01/31/agenda/1043967608_850215.html.

${ }_{54}$ Entrevista a Edward Korry en Salvador Allende vive en la memoria, Op. cit. 
se podía alcanzar el socialismo sin tener que empuñar las armas. Aquella foto tan escasamente castrense de Allende el 11 de septiembre, con el casco y la metralleta entre las manos, junto al relato que Castro hizo de sus últimas horas durante el asalto de los golpistas a La Moneda, fueron la confirmación de su incorporación al panteón de los revolucionarios sin mácula. Una paradoja de la historia, sin duda.

\section{Referencias bibliográficas:}

Aggio, A. (2003): "Uma insólita visita" en Revista História, São Paulo: UNESP, 22 (2).

Alcàzar, J. y Rodrigo, B (2013). : “Allende vs Pinochet, imágenes para la juventud del siglo XXI" en Alcázar, J. y Valenzuela, E. (eds): Chile 73 Memoria, impactos y perspectivas. Editorial PUV/Universidad Alberto Hurtado, Chile.

Alcàzar, J. (2013): Chile en la pantalla, cine para escribir y para enseñar la historia (1970-1998), Valencia-Santiago, PUV-Dirección de Bibliotecas y Archivos de Chile.

Alcàzar, J. y Cáceres, G. (1998): “Allende i la Unitat Popular. Cap a una desconstrucció dels mites polítics xilens" en El contemporani, Revista d'Història.

Alcázar, J. y López, S. (2011): "Fuego cruzado. Guerrillas, dictaduras militares y violaciones masivas de los derechos humanos" en Alcázar Joan (ed): Historia Actual de América latina 1959-2009, Valencia, Editorial Tirant lo Blanch.

Altamirano, C. (1978): Dialéctica de una derrota, Ciudad de México, Siglo XX1.

Debray, R. (1971): Conversación con Allende, México: Siglo XXI.

Del Pozo, J. (1992): Rebeldes, reformistas y revolucionarios. Una historia oral de la izquierda chilena en la época de la Unidad Popular, Santiago, Ediciones Documentas.

"Discurso pronunciado por el comandante Fidel Castro Ruz en el acto conmemorativo del XIII aniversario de los Comités de Defensa de la Revolución, de solidaridad con el heroico pueblo de Chile, y de homenaje póstumo al doctor Salvador Allende, efectuado en la Plaza de la Revolución, José Martí, La Habana, el 28 de septiembre de 1973”, en Timossi, J. (1974): Grandes alamedas. El combate del Presidente Allende, La Habana, Editorial de Ciencias Sociales. 
El Comandante en Jefe Fidel Castro habla sobre la Lucha Armada, entrevista de 1967, en https://www.youtube.com/watch?v=3wM6ioa9rQ\&feature=related [13.05.2015]

El diálogo de América, http://www.panuelosenrebeldia.com.ar/content/ view/228/123/

Entrevista realizada por Augusto Olivares en la Televisión Nacional de Chile en noviembre de 1971 a Salvador Allende y Fidel Castro. El diálogo de América, http://www.panuelosenrebeldia.com.ar/content/view/228/123/

Fermandois, J. (1985): Chile y el mundo, 1970-1973. La política exterior del gobierno de la Unidad Popular y el sistema internacional. Santiago, Ediciones Universidad Católica de Chile.

Fidel en Chile. Textos completos de su diálogo con el pueblo. Santiago de Chile, Empresa editora nacional Quimantú ETDA, 1972.

Kornblum, P. (2004): Pinochet y los archivos secretos. Barcelona, Crítica.

Luna, E. (1998): "Allende y Castro: una entrevista para la historia de América Latina" en Alcàzar, J. y Tabanera, N. (coord): Estudios y materiales para la historia de América Latina, 1955-1990. Valencia, Tirant lo Blanch.

Quiroga, P. (ed) (1989): Salvador Allende. Obras escogidas (1970-1973), Barcelona, Editorial Crítica.

Rodríguez, E. (1995): Crisis y renovación de las izquierdas. De la revolución cubana a Chiapas, pasando por "el caso chileno", Santiago, Editorial Andrés Bello.

Rojas, A. (1998): Salvador Allende: una época en blanco y negro. Aguilar/ El País. Buenos Aires.

Torres, M. (1988): "La nueva batalla de Chile", en El País, Madrid, 1109-1988.

Vázquez, M. (1988): "De lo que fue Santiago ensangrentada", en El País, Madrid, 02-11-1988. 
